\title{
$\mathrm{FH}+\mathrm{H}=$

\section{Territorios virtuales y campos de batalla. El uso de mapas digitales como}

espacios multimedia de estudio y divulgación

Dirección

Clara Martínez Cantón

Gimena del Rio Riande

Francisco Barrón

Secretaría

Romina De León

RHD 6 (2021)

Virtual Territories and Battlefields. The Use of Digital Maps as Multimedia Arena for Research and Outreach

Alejandro Ravazzola

Binar Media

alejandro@binarmedia.tv

Marcelo Vitores

Arqueolab-UBA

marcelovitores@yahoo.com.ar

https://orcid.org/0000-0001-5676-3670

\section{RESUMEN}

El desarrollo tecnológico de las últimas décadas ha proporcionado múltiples posibilidades de comunicación con diversos públicos. Nuevas herramientas y canales complementan y optimizan las preexistentes y exigen también la construcción de nuevos tipos de relato, junto a la conformación de equipos multidisciplinarios que combinen diferentes saberes. En este trabajo exploramos la aplicación de herramientas digitales de registro y difusión al estudio arqueológico-histórico de los conflictos armados y asentamientos militares de frontera de los siglos XVIII y XIX, con fines investigativos académicos y de difusión multiplataforma accesible para un público no especializado.

\section{PALABRAS CLAVE}

Georreferenciación, colaboración abierta distribuida, mapa, multimedia, proyectos.
Carlos Landa

ArqueoLab-UBA

carlosglanda@gmail.com

https://orcid.org/0000-0002-2075-4294

Daniela Avido

ArqueoLab-UBA

danavido@gmail.com

https://orcid.org/0000-0003-3732-9064

\section{ABSTRACT}

The technological development of the last decades has provided multiple possibilities of communication with different audiences. New tools and media complement and optimize existing ones and also require the construction of new types of narratives, together with the formation of multidisciplinary teams that combine different knowhows. In this work we explore the application of digital recording and dissemination tools to the archaeological-historical study of armed conflicts and military outposts of the $18^{\text {th }}$ and $19^{\text {th }}$ centuries, for academic research purposes and multiplatform dissemination accessible to a non-specialized public.

\section{KEYWORDS}

Georeferencing, Crowdsourcing, Map, Multimedia, Projects. 


\section{INTRODUCCIÓN}

El impulso comunicacional que permitió el inusitado desarrollo tecnológico acaecido desde mediados de la década del noventa del siglo pasado ha proporcionado a las ciencias -entre ellas, la Arqueología- posibilidades de difusión imposibles de imaginar apenas unos años antes. En la última década, se han multiplicado las herramientas de registro audiovisual y los canales de difusión del patrimonio arqueológico.

Numerosas experiencias en todo el mundo demuestran que es posible generar el acceso masivo a recorridos virtuales de los sitios arqueológicos y museos a través de internet y del uso de teléfonos inteligentes. Las nuevas tecnologías permiten ampliar in situ la comprensión de los vestigios y la espacialidad de los yacimientos mediante aplicaciones de realidad aumentada. En todos los casos, el acervo documental existente se resignifica al insertarse en un entorno audiovisual digital y los diferentes medios de difusión no se excluyen entre sí, sino que potencian la exposición de las investigaciones de una manera que facilita su actualización y vigencia. A la vez, las réplicas virtuales permiten una manipulación extensa en tanto objetos digitales, lo que da al usuario la oportunidad de experimentar y construir nuevos elementos. $Y$ al igual que con los modelos 3D, mediante los cuales se puede manipular cualquier artefacto de otro modo frágil e inaccesible, también con las cartografías digitales se pueden ensayar múltiples ediciones y selecciones para representar alguna variable de interés, lo que lo transforma en objeto de experimentación y no sólo de contemplación.

Las nuevas herramientas y canales de difusión arqueológica no llegan para desplazar a las anteriores. Las complementan y las optimizan, producen un conocimiento cualitativamente distinto del objeto de investigación, lo que eventualmente permitiría desarrollar otra comprensión de las relaciones entre espacio y cultura, siempre que sean organizadas en una narración que informe y emocione a la vez. Una narración que humanice la investigación académica y la haga accesible también a un público no especializado ya que, de acuerdo con Coleen Morgan (2019), la Arqueología "has the immense potential to [...] resonate with all the passion and fire of science fiction novels, movies, or comic books" (p. 324). A la par, las tecnologías exigen la construcción de nuevos tipos de relato, la conformación de equipos multidisciplinarios, la combinación de diferentes saberes y el aumento de las formas de registro audiovisual en campo que amplíen el uso de los nuevos materiales en conjunto con los soportes de registro y expresión acumulados a través de décadas de investigación.

En este trabajo presentaremos el proyecto Mapa Interactivo de Conflictos Armados (MICA). En su estado actual, el proyecto consiste en un portal web con acceso al prototipo y se prevé el desarrollo de una aplicación para celulares que permita geolocalizar batallas y fortines argentinos del siglo XIX'. En cada punto destacado en el mapa se describe brevemente las circunstancias específicas del hecho histórico y se indexan los enlaces a artículos académicos y contenidos audio-

\footnotetext{
${ }^{1}$ Accesible desde: https://proyectomica.hcommons.org/acceder-al-mapa.
} 
visuales que profundizan y exploran ese lugar y/o acontecimiento bélico. El mapa se transforma en un territorio digital integrador que, lejos de presentar los registros como capas sedimentarias, los aúna dinámica y creativamente.

Este proyecto se inserta en una concepción de la ciencia como una práctica inherentemente participativa, alejado de los modelos verticalistas que imperaron en el mundo académico. De esta forma, la ciencia participativa persigue la interacción a través de proyectos de investigación desarrollados conjuntamente entre científicos y ciudadanos interesados, trabajando de manera voluntaria y colaborativa, en aras de producir conocimientos científicos (Fernández \& Torres, 2016; Acevedo et al., 2018). Es por ello que el proyecto MICA pretende convocar, asistir y compartir las diferentes instancias de su construcción con diversos estudiosos y ciudadanos, fomentando el pensamiento crítico y dialéctico, dentro de un proceso que existe en un continuo hacer: una Arqueología Digital participativa.

\section{REGISTROS Y FORMAS DE LA COMUNICACIÓN}

La virtualidad en Arqueología se constituye como un punto de encuentro entre las Ciencias Sociales y las Humanidades Digitales en el que confluyen herramientas y técnicas de análisis, conservación y puesta en valor (Staropoli et al., 2019). Asimismo, la metodología desarrollada aplicando las tecnologías digitales/virtuales implica un proceso de construcción del conocimiento en el que sujeto y objeto (en este caso las imágenes, los datos georreferenciados) se retroalimentan. En efecto, nosotros como usuarios tenemos injerencia sobre la producción de estas nuevas representaciones, en tanto somos sus creadores/responsables de su existencia, a la vez que dichas representaciones tienen capacidad para intervenir en los procesos de semiosis o de construcción de entramados de representaciones. Siguiendo a Izeta y Cattaneo (2016), consideramos que el proyecto que describimos es un ejercicio de Arqueología Pública.

Los mapas cumplen un rol fundamental durante la investigación, dado que sirven a la vez de guía y de lienzo, como fuente de información conocida y como repositorio de nuevos datos. Pero el potencial de los mapas no se agota en la investigación: son un recurso potente para comunicarse con la sociedad, dentro y fuera de la academia.

Por lo tanto, la comunicación de la investigación arqueológica y los sentidos asignados a las cartografías son dos ejes a considerar para el proyecto MICA. 


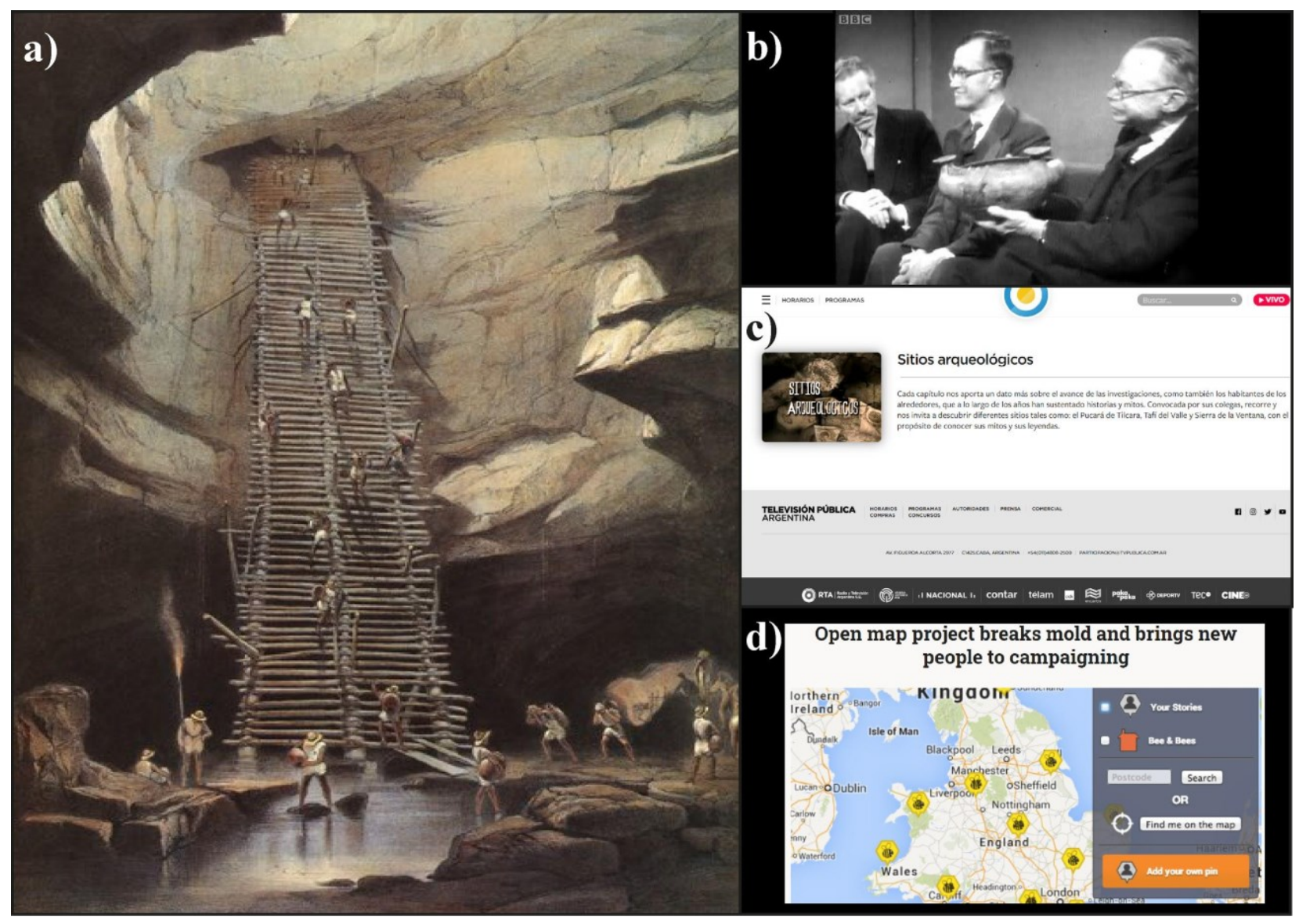

Figura 1. a) Cenote de Bolonchén, Campeche, México. Fuente: Catherwood (1844). b) Animal, vegetable, mineral? Fuente: BBC. c) Sitios arqueológicos. Fuente: TV Pública, Argentina. d) Mapa sobre el cambio climático. Fuente: MobLab (2020).

En todo el mundo han existido iniciativas audiovisuales de difusión arqueológica (figura 1). La ampliación de las vías de difusión audiovisual resulta en una sobreoferta de contenidos. Las nuevas series de divulgación arqueológica deben captar la atención de una audiencia híper fragmentada por innumerables canales abiertos y digitales, plataformas de video on demand (VOD), portales de video por internet y redes sociales. De ahí que creemos imprescindible potenciar y prolongar el acceso al inmenso acervo de contenidos audiovisuales que se genera, mayormente gracias al apoyo estatal, reutilizándolos en herramientas digitales de divulgación como son los mapas interactivos, integrando no sólo contenidos audiovisuales actuales y pasados, sino también documentos escritos, cartografías y fotografías de todas las épocas, con fines transversales que coexisten armónicamente, desde educar e investigar, conservar el patrimonio, hasta promover el turismo regional, a la vez de ser una fuente de conocimiento entretenido y sencillo de compartir.

Por su parte, la cartografía constituye una reflexión en torno al espacio plasmada en diversos soportes (cueros, rocas, papiros, etcétera) desde la antigüedad y factible de ser difundida (Greenfieldboyce, 2014; Porro Gutiérrez, 2011; Redman, 1990). El surgimiento de los estados ha sido un fuerte incentivo para el desarrollo de catastros, mapas territoriales y cosmológicos, muchas veces entrelazados (figura 2). Desde entonces, las constantes migraciones de nuestra especie hicieron de ellos elementos imprescindibles en sus periplos. El desarrollo de la imprenta y luego la revolución digital los impulsaron a formas impensables apenas siglos atrás y a escalas de reproducción 
y accesibilidad inusitadas. Sobra decir que, como en otras disciplinas, en la Arqueología se adecuaron tempranamente convenciones cartográficas como herramienta de investigación y difusión (Mortillet \& Chantre, 1876). Actualmente la relevancia de la cartografía arqueológica continúa, no como una mera ilustración de la ubicación de sitios sino como una herramienta de análisis para la investigación y como una tecnología para la gestión del patrimonio (por ejemplo, el proyecto Lap$\left.\mathrm{pu}^{2}\right)$.

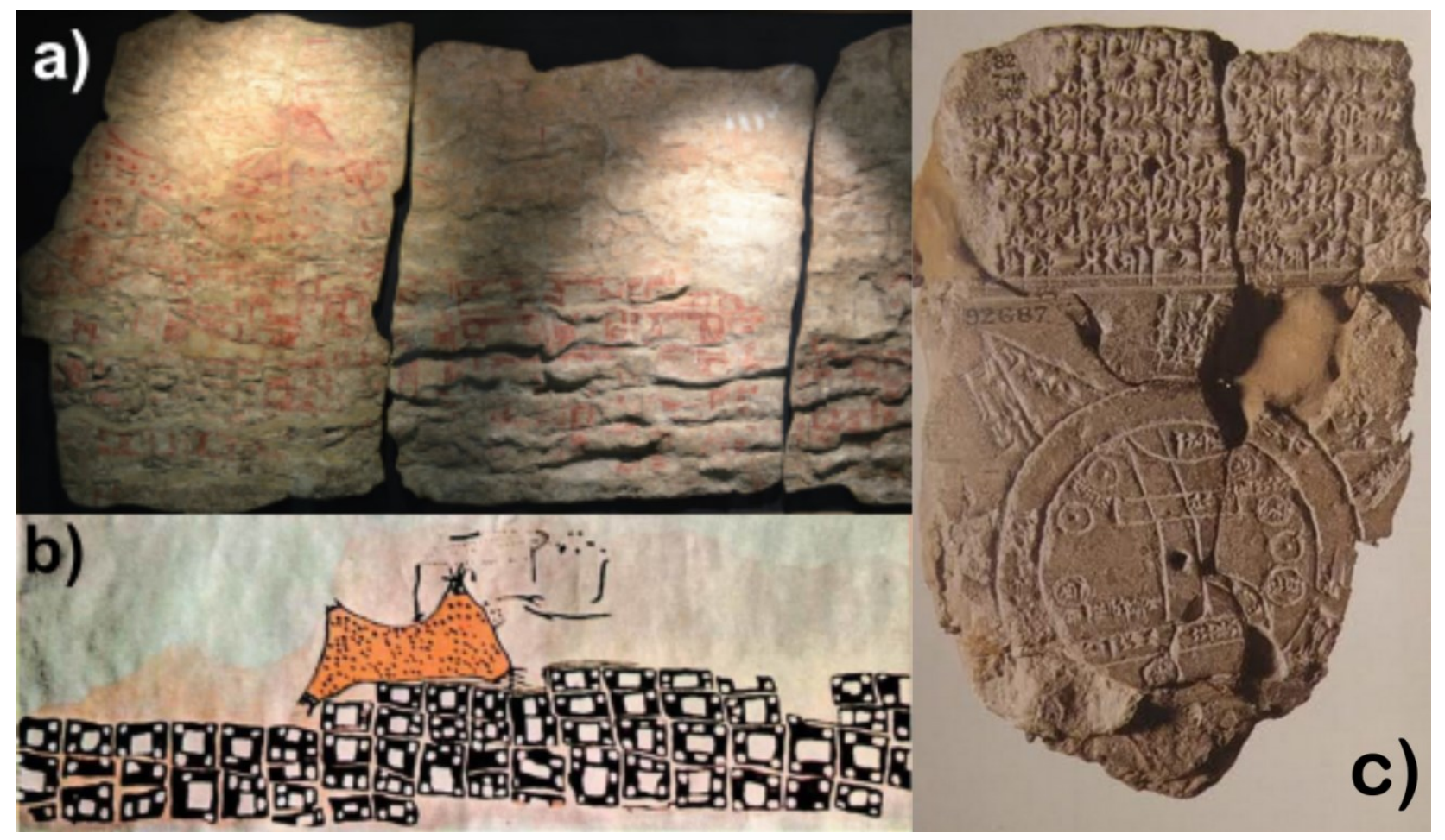

Figura 2. a) pintura mural en el sitio neolítico de Catalhöyuk (Turquía) que se interpretó podría representar un mapa del asentamiento. Fuente: Greenfieldboyce (2014). b) Copia de los motivos del mural de Catalhöyuk. Fuente: Catalhöyük Project. c) Tablilla posterior al 700 a.C., conocida como mapa babilónico del mundo y que combina regiones maravillosas y otras reales. Fuente: British Museum.

Los mapas no son neutros ni ingenuos; expresan en sus trazos y de forma condensada ideologías, estilos, referencias geográficas, imaginarios, recursos. Elaborar mapas siempre es elaborar representaciones culturales; elaborar mapas constituye una práctica discursiva, una narrativa. Los mapas son también recorridos por formas de pensar y proyectar así como de maneras de hacer y ser en el espacio; también de ocultar y olvidar. Todo mapa conlleva un romance con la imaginación. Por medio de símbolos, estas maneras de observar y pensar la espacialidad manifiestas en las cartas, aportan información de aspectos económicos, sociales y políticos (Coll, 2009; Lois, 2014). Todo mapa comunica, selecciona y omite, ilumina y esconde. Puntualmente hacia fines del siglo XIX, las mejoras técnicas que posibilitaron el desarrollo y difusión de la cartografía moderna impulsaron la utilización de mapas no solamente como herramientas burocráticas de regulación social y control de los territorios que pasan a conformar parte de los estados nacionales, sino también como método para crear, enseñar y divulgar representaciones espaciales vinculadas a temáti-

${ }^{2}$ Accesible desde: hitpss//mww.hnuce.edu.uy/index.php/ciencias-antropologicas/departamento-de-arquedogia/proyedtos/lappu. 
cas de interés (soberanía, exploración científica, conocimientos del territorio, flora, fauna, geología; entre otras). Es así que libros, diarios, revistas, historietas y filmes comienzan a utilizar mapas con fines pedagógicos y de entretenimiento (Lois, 2014).

A lo largo de los últimos 25 años la cartografía, como forma de representar los mundos, se resignificó radicalmente. Debido al desarrollo de internet, del acceso masivo a GPS (Global Positioning System; en español, Sistema de Posicionamiento Global), de los Sistemas de Información Geográfica (SIG) libres, de la liberación, digitalización y puesta en línea de múltiples bases de datos cartográficos, y del desarrollo de plataformas open source de crowdmapping y del relativo fácil acceso a dispositivos móviles inteligentes con conexión de datos (celulares, tablets, e-books, laptops, relojes), los mapas pasaron de ser meras representaciones estáticas de un determinado territorio (muchas veces desactualizadas) para convertirse en archivos vivos (Gallardo Escalona, 2013). Estos posibilitan a los sujetos visualizar, comprender y aportar al conocimiento (muchas veces, en tiempo real) de situaciones, procesos y sistemas concretos, tales como marcar áreas de inseguridad, gestionar situaciones de crisis (como la actual pandemia de COVID-19), controlar zonas y eventos, y generar conciencia y acciones con respecto al cambio climático. Tal es el caso de los proyectos Friends of the Earth ${ }^{3}$, Climate Change Coders ${ }^{4}$ y Moblab 5 (figura 1d). Ya sea el trazo de tinta de un experto navegante o una construcción colectiva utilizando los software más complejos, el mapa es siempre una narrativa que, como cualquier herramienta, puede ponerse al servicio de un amplio espectro de actores sociales (desde su aplicación por parte de gobiernos fascistas al empleo de ciudadanos empoderados). Lo relevante del proyecto MICA es que considerando siempre que los mapas nos cuentan historias, será en honor a ellas que debemos tener en cuenta qué, cómo, con y para quiénes contarlas.

La práctica colaborativa de confeccionar mapas digitales interactivos por parte de diversos colectivos se denomina -recurriendo una vez más a anglicismos- crowdmapping (mapeo de multitudes). Los datos aportados por los usuarios se suben y almacenan en plataformas tales como Google Maps, OpenStreetMap, Crowdmaps, StoryMaps, ArcGis, Storymap.knightlab; entre otras, muchas veces generando verdaderas comunidades virtuales. Es así que la cartografía digital permite adjuntar como información geolocalizada aquellos registros históricos desarrollados previamente en soportes tales como dibujo, fotografía, audio, película. Otro antecedente lo constituye History $\mathrm{Pin}^{6}$, un portal de storytelling cuyo aspecto de cartelera o pizarra de anuncios permite publicar imágenes individuales o crear colecciones. Al cargar las imágenes y asignarles coordenadas espacio-temporales y otros metadatos, se puede contribuir colectivamente tanto al relato de un evento o serie de eventos como a temáticas particulares. Una ventaja de este recurso es que su gestión es sencilla y permite incluso el trabajo colaborativo, recopilando contribuciones de distintos aportantes, una característica deseable para un emprendimiento de ciencia participativa (por ejemplo,

\footnotetext{
3 Accesible desde: http://www.foe.co.uk.

4 Accesible desde: http://www.cccoders.org/.

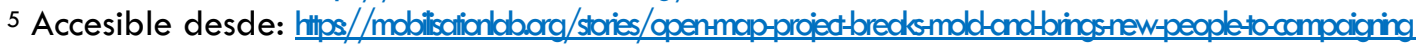

6 Accesible desde: https://www.historypin.org.
} 
World War ( Panoramas 7 ).

Más de un siglo y medio después de las apariciones en periódicos de los primeros registros arqueológicos hechos a lápiz, las herramientas de registro se multiplicaron: fotografía, fotografía aérea, fotografía de alta resolución (Gigapan) con análisis espectral (DStretch), imágenes satelitales, video, video y fotografía $360^{\circ}$, fotogrametría y modelado 3D, cámara térmica, escaneo láser, escaneo óptico, georradar, sonar de barrido lateral, etcétera. En el caso de los medios de difusión, al libro y la prensa escrita se sumaron las salas de cine, las radios, la televisión, el VHS, el DVD, el streaming on demand, las redes sociales, las aplicaciones celulares e internet. Estas últimas ofrecen la experiencia de conocer el patrimonio cultural por medio de la realidad virtual (entornos 3D generados por computadora), la realidad aumentada (inclusión de objetos 3D e información gráfica superpuestos sobre imágenes del mundo real) y la realidad mixta o híbrida (combinación de elementos reales y virtuales en un mismo entorno sobre el que, a su vez, se pueden superponer elementos de realidad aumentada).

Es en y con estas nuevas tecnologías donde abreva y se cifra el proyecto MICA, presentando al visitante/colaborador un escenario espacial dinámico e interactivo en el que adentrarse en profundidad, donde son combinables diversos elementos digitales (cartografías, textos, fotos, enlaces), con la ventaja de prescindir de la instalación programas o la descarga de datasets completos para acceder a la información deseada (Ellenberger, 2017).

\section{ANTECEDENTES DE INTEGRACIÓN DE HERRAMIENTAS TECNOLÓGICAS DE EXPLORACIÓN Y DIFUSIÓN EN ARQUEOLOGÍA}

Diversos proyectos proveen ejemplos sobre las posibilidades de integración de tecnologías multimediales para la documentación y comunicación en Arqueología, la construcción de narrativas interactivas y los ejes sobre los cuales pueden establecerse éstas -por ejemplo, temporales, geográficos o temáticos.

A fines de 2016, en Oxkintok, una de las ciudades mayas que visitaron Stephens y Catherwood (1993 [1854]), uno de los autores de este trabajo -Alejandro Ravazzola- formó parte del equipo que produjo un registro audiovisual que hizo provecho de múltiples y variadas herramientas tecnológicas para generar contenidos audiovisuales multiplataforma, tanto con fines de divulgación como académicos. Especialistas del Instituto Nacional de Arqueología e Historia de México (INAH), de la National Geographic Society y del Center of Interdisciplinary Science for Art, Architecture and Archaeology (CISA3, Universidad de California en San Diego) realizaron el estudio detallado de un edificio único en toda el área maya, el Tzat Tzun Tzat o Satunsat, una estructura laberíntica de tres pisos que representa los tres niveles del universo según la cosmovisión maya. También, se relevaron pinturas rupestres en la cercana caverna de Aktun Usil, ubicada dentro de los límites del sitio de Oxkintok y que fuera en la antigüedad utilizada con fines rituales.

\footnotetext{
7 Accesible desde: https://www.historypin.org/en/world-war-i-panoramas/.

8 Accesible desde: https://youtu.be/PDI2nM6viQY.
} 
El Satunsat fue fotografiado con un dron y a la vez escaneado exterior e interiormente con un scanner laser $3 D^{8}$. También se fotografió detalladamente su interior. Todas las imágenes digitales fueron integradas para crear un modelo 3D exacto del edificio que fue publicado en dos versiones:

- Como un objeto 3D manipulable en el portal Sketchfab, con un recorrido tanto libre como programado, que suma textos y fotografías?

- Como una pieza de realidad virtual en la cual se puede navegar libremente, mediante lentes específicos, por la proyección en domos o pantallas $360^{\circ} \circ$ en la propia pantalla de una computadora ${ }^{10}$.

También, se llevó a cabo un registro de la exploración del laberinto en video $360^{\circ}$, que fue narrado en una pieza de menos de un minuto de duración y que fue publicado en YouTube y redes sociales, llegando a alcanzar dos millones de reproducciones en Facebook ${ }^{1}$.

En la caverna de Aktun Usil se registraron las pinturas del techo con tecnología Gigapan, que permite obtener una imagen de alta resolución a partir de un mosaico fotográfico, que puede ser ampliada con un elevado nivel de detalle sin perder calidad. Esa fotografía a su vez fue procesada con el software DStretch ${ }^{12}$ para destacar líneas y colores poco perceptibles a simple vista, mediante la técnica de decorrelation streching, que mejora o exagera la separación de color de una imagen para posibilitar una reinterpretación visual ${ }^{13}$.

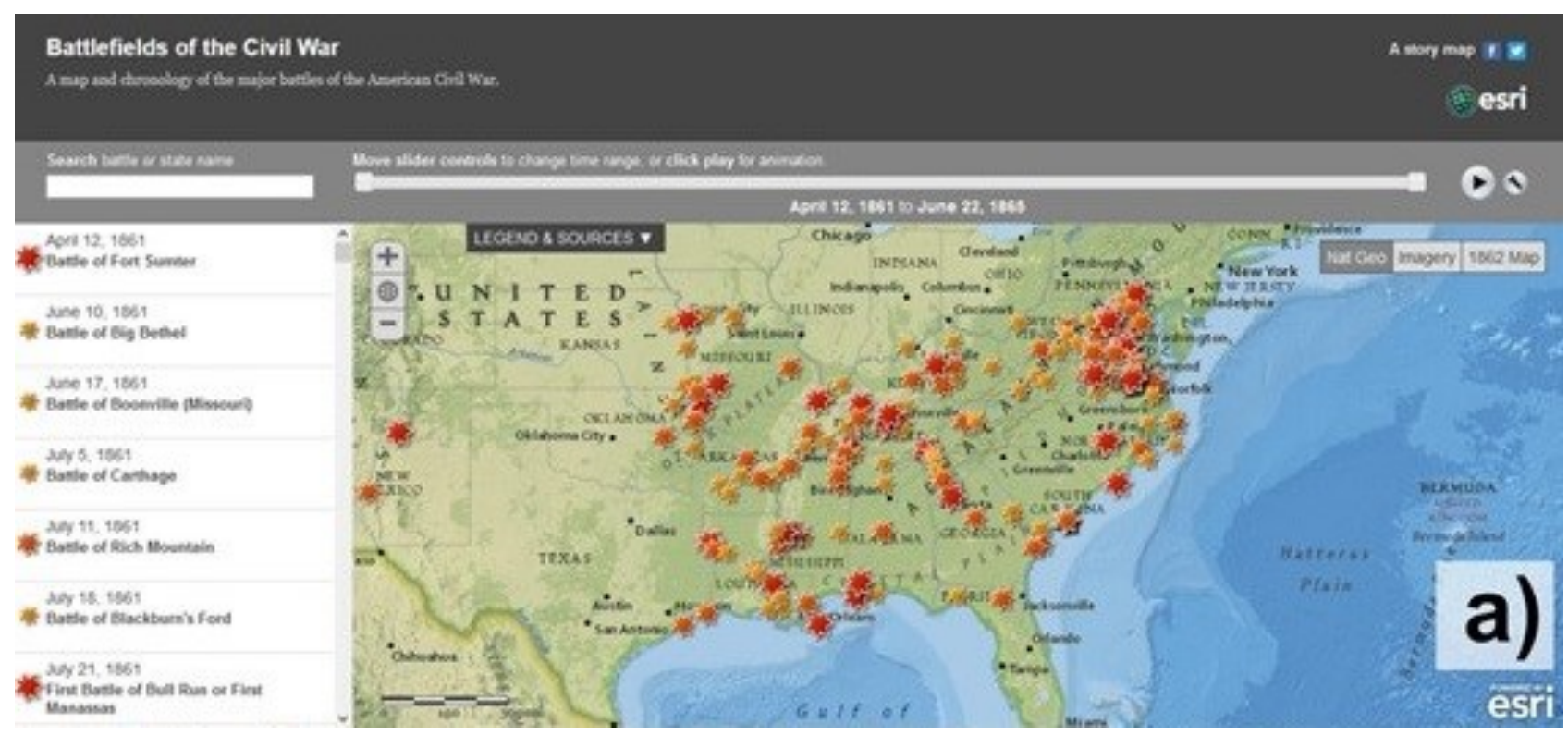

Figura 3a. Diseños varios de interfaces: Mapa de las batallas de la Guerra Civil norteamericana. Fuente: American Battlefields Trust.

\footnotetext{
9 Accesible desde: https://sketchfab.com/models/e584ef023c9541c19e466befcc7a5e4a.

10 Accesible desde: http://67.58.52.141:9999/oxki/.

11 Accesible desde: https://www.youtube.com/watch?v=eonS8OdeoPE.

12 Accesible desde: https://www.dstretch.com.

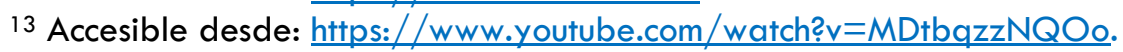




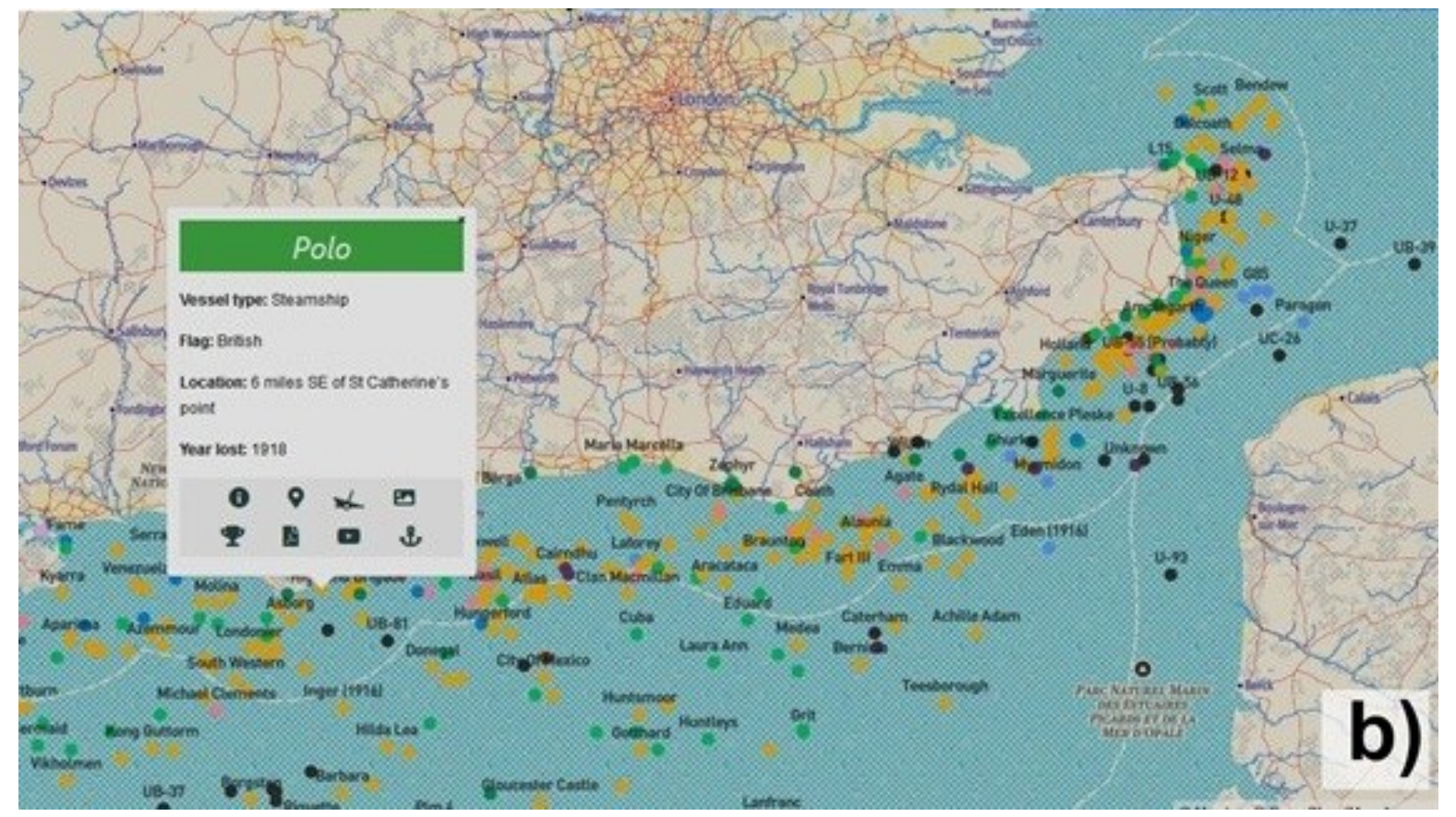

Figura 3b. Diseños varios de interfaces: Mapa de los Naufragios en el Canal de la Mancha durante la Primera Guerra Mundial. Fuente: Forgotten Wrecks of the First World War.

La campaña, en su totalidad, fue registrada como parte de un documental de una hora de duración llamado Misterios del Inframundo, comisionado por National Geographic para su canal de cable y su aplicación VOD 14.

Cada acción de registro fue narrada también en piezas audiovisuales de corta duración para ser publicadas en redes sociales. A su vez, el material obtenido dio base a diversas publicaciones académicas (Rissolo et al., 2019) y el modelo 3D del laberinto Satunsat permitiría llevar a cabo mediciones arqueoastrónomicas relativas a las funciones calendáricas de la estructura, sin tener que esperar a realizarlas in situ en fechas específicas del año ${ }^{15}$.

El registro audiovisual multiplataforma llevado a cabo en Oxkintok constituyó una experiencia que demostró la posibilidad de desarrollar estudios científicos aplicando tecnología y herramientas de avanzada con fines académicos y a la vez crear una narración documental destinada a un público masivo. También, el proyecto buscó diversificar el uso de las piezas audiovisuales en diferentes formatos y duraciones, con la idea de que cada una funcionara en canales de difusión específicos y de manera complementaria. Así, el video $360^{\circ}$, las piezas de realidad virtual y los vídeos cortos en redes sociales buscaron potenciar al documental televisivo y viceversa. Al mismo tiempo, los diferentes contenidos divulgaron las técnicas utilizadas y los resultados obtenidos, conformando un ecosistema de metadiscursos coordinados que brindaron experiencias visuales pasivas (tv, videos en redes sociales) y activas (video $360^{\circ}$ y realidad virtual) con las cuales el usuario podría experimentar la sensación de explorar el mundo maya en sus múltiples dimensiones.

En este caso la multiplicidad de los recursos se ancla al focalizar en el sitio de Oxkintok. Pero para temáticas abiertas, tanto en la cantidad de contenidos como en las fuentes de producción de éstos, se requiere una estrategia de comunicación que apele a algún eje aglutinante. Un

\footnotetext{
${ }_{14}$ Accesible desde: https://www.nationalgeographicla.com/video/tv/misterios-del-inframundo.

15 Accesible desde: https://www.youtube.com/watch?v=MDtbqzzNQOo.
} 
ejemplo de ello son los mapas interactivos, donde un territorio virtualizado es la dimensión sobre la que se despliegan las narraciones potenciales.

Existen algunas referencias ya existentes, siendo la del Mapa de los Naufragios en el Canal de la Mancha durante la Primera Guerra Mundial, uno de los más importantes Forgotten Wrecks ${ }^{16}$, ya que logra posicionar todos los naufragios acontecidos en esas aguas durante dicho conflicto bélico, reuniendo en cada punto los links a artículos científicos, videos de YouTube, fotogrametría de vestigios, etcétera (figura 3b). Además, es posible segmentar la exploración por año, nacionalidad y/o tipo de embarcación. Otro caso es el del proyecto francés sobre la Arqueología de la Gran Guerra ${ }^{17}$ donde confluyen en un mismo territorio virtual relatos, fotos, planos, audios, etcétera. También el excelente trabajo del American Battlefields Trust ${ }^{18}$ sobre la Guerra Civil de Estados Unidos $^{19}$ (figura 3a) que utiliza, entre otras, Arcgis Storymaps para la creación de relatos georreferenciados, y Google Poly para programar tours virtuales y compartir modelos 3D. Una línea de tiempo sobre el mapa permite entender el desarrollo del conflicto sobre el territorio desde su comienzo hasta el final, lo que habilita una comprensión contextual y nuevas interpretaciones invitando al usuario a su recorrido. Por último, un claro ejemplo de construcción colectiva es FortFinder20, un mapa interactivo de fortificaciones y construcciones militares en general, donde los usuarios pueden realizar una carga inicial de un lugar con su descripción, categorización y fotos que, tras ser chequeadas por los administradores es publicado online.

En cuanto a casos de aplicación exitosa de realidad virtual y aumentada en nuestro país se debe mencionar el del Complejo Museológico de San Lorenzo, realizado por el DC Team de la Universidad Nacional de Rosario21. La propuesta incluyó la implementación de tecnologías de realidad virtual, video $360^{\circ}$, pantallas multitouch para infografías interactivas y una aplicación de realidad aumentada para tablets y celulares que se activa al encuadrar piezas del museo. También vale citar un proyecto en Tandil 22 que busca reutilizar los modelos $3 \mathrm{D}$ creados para una aventura gráfica basada en hechos históricos para ser utilizadas también en aplicaciones de realidad virtual y aumentada ${ }^{23}$ con el objetivo de divulgar in situ el patrimonio histórico y arqueológico de la ciudad. Por último, en Uruguay se realizó Frigorífico Anglo en Fray Bentos ${ }^{24}$, una aplicación de exploración interactiva de los naufragios de la Bahía de Maldonado ${ }^{25}$ y, en la misma zona, se realizó la fotogrametría 3D subacuática del barco de guerra inglés Agamemnon, que se hundiera junto a la isla Gorriti26.

\footnotetext{
16 Accesible desde: https://map.forgottenwrecks.org.

17 Accesible desde: http://archeologie 1 418.culture.fr/fr/ 11 -largonne-un-secteur-idealement-conserve.html.

18 Accesible desde: https://www.battlefields.org/visit/battlefields.

19 Accesible desde: https://storymaps.esri.com/stories/civilwar/.

20 Accesible desde: https://fsgfort.com/fortfinder/.

21 Accesible desde: hitp://www.damteam.com.ar/3/transmedia/50/Plan-de-Modemizacion-Complejo-Museologica-San-Lorenzo.

22 Accesible desde: http://www.fronterasdelindependencia.com/index.php/es/arte.

23 Accesible desde: http://www.unimmerse.com.ar.

24 Accesible desde: www.patrimonioanglo.com/\#proyecto.

25 Accesible desde: https://cipac.cure.edu.uy/museo-virtual-cipac/.

26 Accesible desde: https://leblob.fr/techno/tresors-epaves-en-3d.
} 
Desarrollamos el proyecto MICA considerando estos casos y teniendo en cuenta las múltiples ventajas creativas que brindan las diversas herramientas tecnológicas mencionadas tanto para la investigación como para la difusión pública del conocimiento científico. Esperamos que confluyan en él los intereses y anhelos de una ciudadanía ávida por participar, conocer, compartir e impulsar ciencia.

\section{MAPA INTERACTIVO DE CONFLICTOS ARMADOS: PROYECTO MICA}

El estudio de sitios arqueológicos históricos relacionados con eventos bélicos y conflictos durante los siglos XVIII y XIX en diversas regiones del país (asentamientos militares, indígenas y rurales así como los campos de batalla), llevados a cabo por diversos investigadores desde la década del noventa en adelante, han aportado información relevante sobre diversos aspectos de los procesos socio-culturales allí acaecidos (Gómez Romero \& Spota, 2006; Landa \& Hernández de Lara, 2014). La publicación de dichas investigaciones en diversas reuniones científicas así como en revistas de su especialidad, constituyen materiales primordiales como contenidos plausibles de ser aportados al proyecto MICA. Lo mismo puede extenderse a la producción antropológica histórica, a la etnohistórica y a la histórica, entre otras disciplinas. Lo relevante es que esa información pueda ser georreferenciada.

La lógica misma de la investigación en la arqueología del conflicto es la de un rompecabezas que incorpora materiales diversos (documentos escritos, esculturas, pinturas, fotografías, cartografías, memoria oral y objetos hallados en excavaciones), y que recurre a técnicas y saberes variados (dataciones, estudios de balística y armamento histórico, monumentalidades, Arqueología experimental, análisis de huesos, metales y tejidos, etcétera), aconteciendo en diversos y disímiles escenarios: espacios naturales abiertos y extensos, sitios subacuáticos, bibliotecas, pinacotecas, archivos, museos, laboratorios, casas de familia, comunidades originarias, etcétera. Precisamente, el paisaje se torna protagonista para la construcción de un relato multimedia de la arqueología de fuertes, fortines, asentamientos indígenas históricos y campos de batalla. Es por ello que la imagen del territorio en forma de mapa sirve como un lienzo sobre el cual diseñar un relato georreferenciado que contenga todos los contenidos existentes y por registrar. Esta idea tiene el potencial de hacerse extensible a cualquier proceso de índole arqueológico e histórico que se desee abordar.

El desarrollo de una serie documental, producida durante los años 2020 y 2021 para TV y VOD (Canal Encuentro y plataforma Cont.ar), llamada Memorias del Frente 27 sobre Arqueología de campos de batalla constituye una oportunidad que permite concretar un plan de producción que, si bien tiene como prioridad realizar cuatro episodios de larga duración y ocho cortos para la web, también posibilitaría sumar nuevos datos y dar visibilidad al proyecto MICA sobre fuertes, fortines y campos de batalla de los siglos XVIII y XIX en el país. De esta forma, el desarrollo de la serie se erige en génesis de un proyecto complementario y extensivo, constituyendo el puntapié inicial para

${ }^{27}$ Accesible desde: http://encuentro.gob.ar/programas/serie/10552/10553/. 
la creación un territorio virtual de análisis y comunicación en donde convivan los acervos generados durante su producción con aquellos generados por investigadores a lo largo de décadas de trabajos y aquellos que, aprobación mediante aporten los usuarios. Esta labor colectiva, esta cartografía participativa, es lo que hemos denominado MICA.

Influidos por los antecedentes mencionados, hemos desarrollado un corpus preliminar mediado por la interfaz de un mapa (figura 4) - constituido por fuentes históricas, arqueológicas, antropológicas, geográficas (como, por ejemplo, la de la Editorial Universitaria del Ejército ${ }^{28}$ ) y también del registro de algunas campañas de trabajo de campo realizadas en los últimos años en los sitios correspondientes a las batallas de La Verde, Vuelta de Obligado, Piragüil, Carmen de Patagones y San Antonio de Iraola, y en los fortines Otamendi, Miñana y El Ciudadano. Si bien puede ser objeto de debate, consideramos que la selección de los eventos pertinentes debe realizarse teniendo en cuenta definiciones de carácter abierto de conflicto armado, comprendiendo a los mismos como "the use of organised lethal force by one group against another" (Christiensen, 2004 , p. 130), dado su carácter laxo, abarcativo e inclusivo.

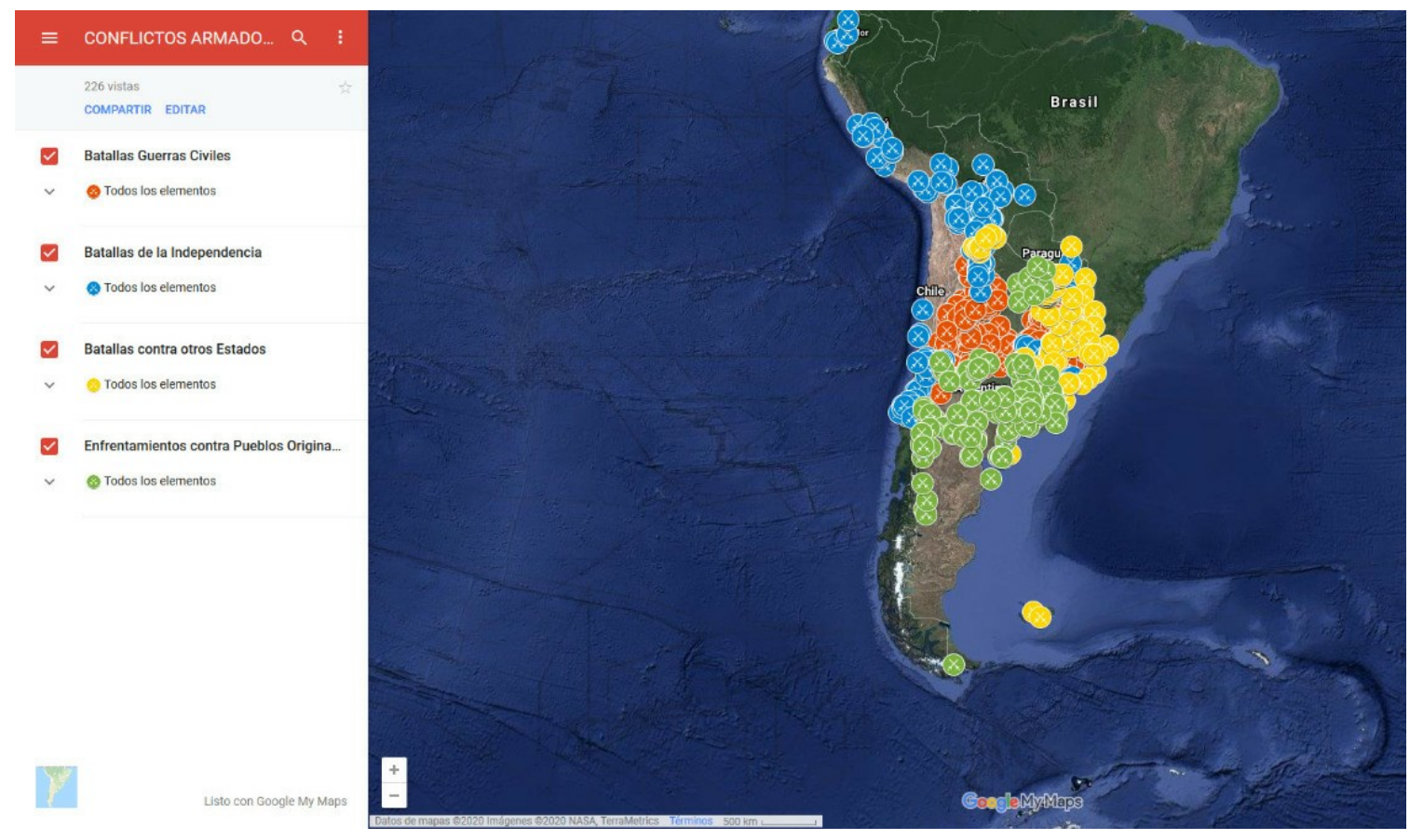

Figura 4. Diseño general de interfaz del prototipo de MICA. Fuente: elaboración propia.

El contenido que actualmente forma parte del corpus MICA en una primera instancia fue producido, cotejado y desarrollado por un comité de moderadores dando por resultado un prototipo plausible de ser visto pero no modificado por los visitantes al sitio. Para una segunda instancia se contempla la apertura a usuarios generales que puedan aportar información y materiales de manera electrónica, que se publicarán en caso de ser aprobados, luego de ser evaluados y formateados por dicho comité. Así, el proyecto MICA se propone como una herramienta abierta de divulgación y creación de conocimiento donde se rompe el límite entre los roles de usuario y de genera-

${ }^{28}$ Accesible desde: http://www.iese.edu.ar/EUDE/?page id=2917. 
dor de contenido, asegurando calidad académica.

Si bien el proyecto MICA no se reduce a una disciplina y le cabe situarse y reinterpretarse dentro de los recorridos de otras ramas de las Ciencias Sociales, por la conformación y motivación inicial del equipo de trabajo, corresponde referirlo en el cruce de la Arqueología con las Ciencias de la Comunicación. Se prevé ampliar la diversidad del comité de moderadores para que sea interdisciplinario.

La intención de realizar este prototipo es dar un primer paso que nos lleve a concretar un mapa interactivo que sea accesible desde una página web y una aplicación donde estarán geoposicionados los asentamientos militares de frontera y todas las batallas, que podrán verse juntos - por separado, y según el año que se elija en una línea de tiempo. Un mapa en el que también podrán programarse recorridos narrativos que les den sentido histórico y geográfico a los sitios.

Si bien en esta primera etapa el mapa no tiene una página web dedicada ni una app, puede accederse al prototipo en la página del proyecto ${ }^{29}$. A la fecha el contenido está disponible para visualizarse, sin que los usuarios puedan realizar modificaciones.

En suma, al clickear en cada punto, ya sea fortín o batalla, se desplegará el menú de contenidos posibles (figura 5):

- Fotos y Videos de los sitios y de las exploraciones científicas.

- Fotos de alta resolución Gigapan.

- Fotos con realidad aumentada donde se verán los fortines en 3D.

- Links a recorridos virtuales con fotos $360^{\circ}$ en Google Expeditions o Storysphere.

- Links a videos $360^{\circ}$ en YouTube VR 3D.

- Fotogrametrías 3D de objetos hallados, alojados en Sketchfab.

- Imágenes aéreas de los sitios, ya sea de dron o editadas con Google Earth View.

- Intervención gráfica de las imágenes de dron con la planta de un fortín o la distribución y los movimientos de tropa en una batalla.

- Links a noticias relacionadas en la prensa.

- Fotos, mapas, documentos y pinturas históricos.

- Piezas de data visualization ${ }^{30}$.

- Artículos científicos alojados en repositorios institucionales como SEDICl ○ RICONICET, repositorios abiertos como CORE o Acta Académica, o diversas redes sociales académicas comerciales ${ }^{31}$.

- Imágenes microscópicas de análisis óseos, metalúrgicos, vegetales o textiles.

- Libros sobre temáticas vinculadas al sitio y/o evento en PDF.

- Historietas sobre batallas en formato PDF.

\footnotetext{
29 Véase nota anterior.

30 Accesible desde: https://vimeo.com/128373915.

31 SEDICl, accesible desde: http://sedici.unlp.edu.ar, RI-CONICET, accesible desde: https://ri.conicet.gov.ar, CORE, accesible desde: http://core.ac.uk y Acta Académica, accesible desde: www.aacademica.org.
} 


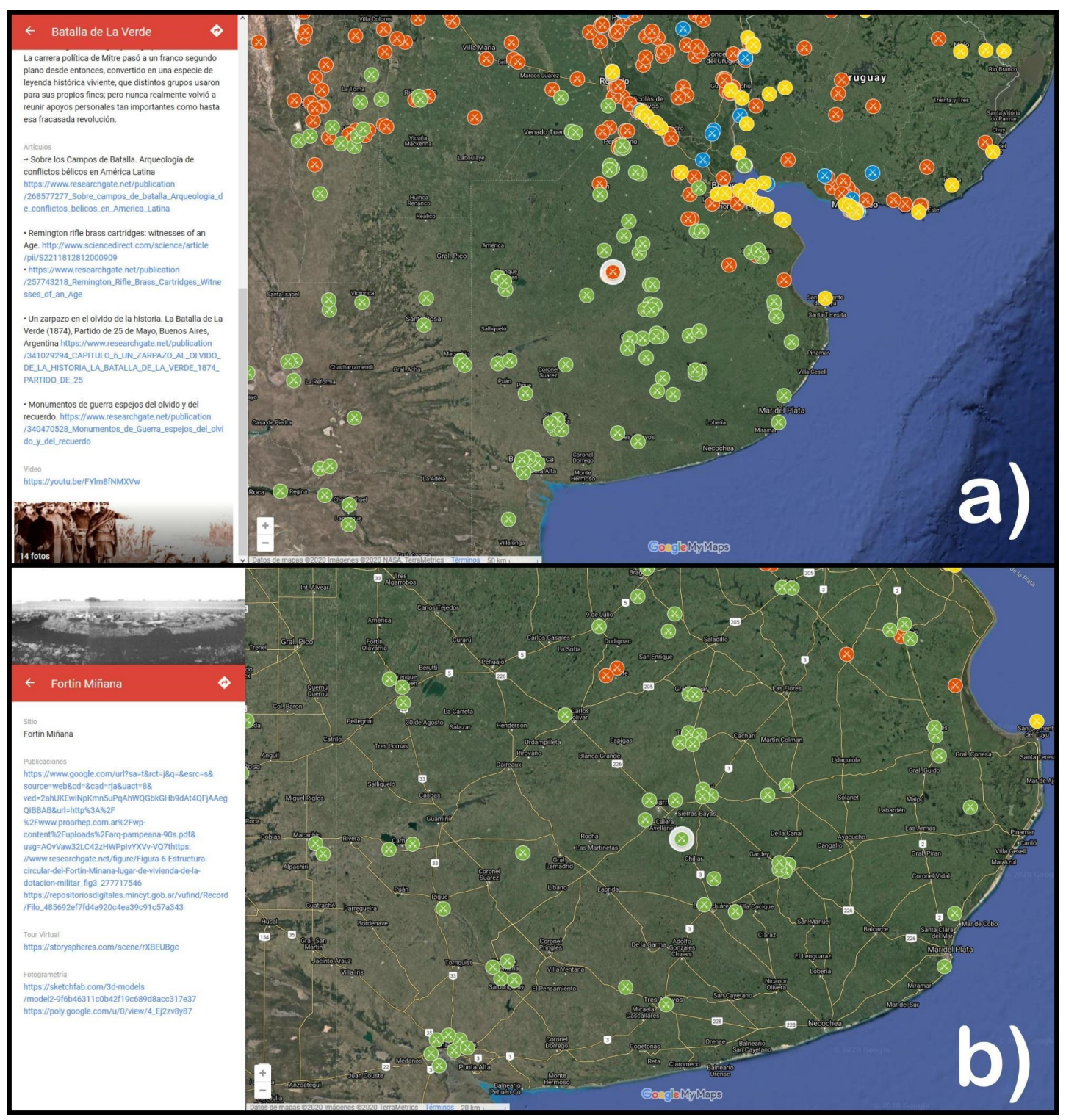

Figura 5. Diseño de interfaz del prototipo de MICA al seleccionar uno de los puntos para previsualizar los datos disponibles. a) Batalla La Verde. Fuente: elaboración propia. b) Fortín Miñana. Fuente: elaboración propia.

El proyecto presenta una serie de ventajas:

- Es un corpus multimedia que se renueva y amplía en el tiempo.

- Nuclea la información existente en el tema hasta convertirse en una fuente de referencia.

- Abre la posibilidad de articulaciones con empresas de tecnología, como Google, Faro, Sketchfab, e instituciones y equipos académicos especializadas, como el Instituto Geográfico Nacional (IGN), DCTeam, etcétera.

- Su información se conserva en nubes de almacenamiento siendo accesible desde cualquier dispositivo con conexión a la red.

- Es una poderosa herramienta académica educativa, a la vez que un portal de información entretenida y de aplicación en turismo cultural.

- Pueden aplicarse o incorporar nuevas capas que aborden otros procesos, temáticas o periodos arqueológicos: poblamiento americano, periodo formativo, marítima, in- 
dustrial, etcétera.

- Es una forma de aprendizaje que parte de la construcción colectiva.

De esta forma el desarrollo del proyecto MICA puede ser de utilidad como modelo-guía a otros proyectos de índole similar, al constituirse en un antecedente válido a tener en cuenta.

El uso de las tecnologías de registro necesarias es accesible en términos de recursos y disponibilidad. Pueden utilizarse dispositivos y programas que no implican un costo elevado y que están al alcance de la gran mayoría de los investigadores sólo con disponer de una cámara, un celular o tablet y una computadora portátil. En muchos casos, puede conseguirse que los especialistas y los equipos técnicos sean provistos por instituciones académicas mediante alianzas en donde se complementen los objetivos de todas las partes involucradas. Por otra parte, las empresas proveedoras de tecnología pueden estar abiertas a ceder el uso de sus instrumentos y cámaras a cambio de la difusión resultante.

Recapitulando, se aspira a crear una base de datos multimedia que se renueve y amplíe en el tiempo, que sea capaz de nuclear la totalidad de la información existente sobre el tema hasta el punto de convertirse en una fuente de referencia (Cook et al., 2018) y que posibilite una intensa experiencia con el pasado y poder apreciar aquello que ha sido y que ya no existe. Apostar al desarrollo de contenidos web y de realidad virtual y aumentada, potencia y prolonga la exposición de relatos audiovisuales por canales tradicionales, mientras que éstos acrecientan el sentido y estimulan al usuario a experimentarlos. Como señala Kate Ellenberger (2017): "Virtual and augmented reality are promising tools we can use to inspire members of the public to focus and empathize with past peoples" (p. 308). Al mismo tiempo, se maximizan los recursos invertidos en la producción. El proyecto MICA, haciendo suyas las palabras de la geógrafa argentina Carla Lois (2015), parte de:

(...) una definición amplia, flexible e inclusiva de mapa, comprendiéndolo como una forma de representación gráfica que facilita el conocimiento espacial de cosas, conceptos, condiciones, procesos o eventos que conciernen al mundo humano (p. 2).

Es de esta forma que múltiples elementos particulares - plausibles ellos mismos de ser mapas- se condensan para dar forma a un recorrido colaborativo y participativo por numerosos episodios violentos que signaron nuestra historia así como por las trazas, huellas y relictos que han dejado.

Actualmente -diciembre 2020-, el prototipo cuenta con 918 registros georreferenciados de conflictos armados, que contienen una diversidad de datos textuales y audiovisuales, abarcando el siglo XIX hasta las primeras décadas del siglo XX, principalmente en América del Sur, vinculados a la Argentina, si bien no es el objetivo último del proyecto este recorte. Se deja abierto el abarcar una escala espacial y temporal más amplia, incluyendo conflictos coloniales y prehispánicos, entre otros. Existe una dimensión adicional que hace que sea especialmente interesante enfocar toda la batería de recursos narrativos mencionados al tema de los conflictos armados que acontecieron durante la conformación del Estado Argentino. Las huellas -tanto materiales como mnemónicas- de los enfrentamientos pasados se mantienen vigentes y existe un interés de gran parte de la pobla- 
ción por tratar de entender el presente a partir de las luchas que nos precedieron. Consideramos que, como herederos de los conflictos históricos $y$, en ese sentido, interpelados por un pasado en común más allá de las pertenencias culturales, étnicas e ideológicas, todas esas huellas nos interpelan. Por ende, deben ser incluidas y visibilizadas como parte de la memoria colectiva en perpetua construcción.

En la elaboración inicial de MICA, la clasificación de los registros se hizo con categorías provisorias, de momento ordenadas como un campo con variables excluyentes: batallas de independencia, guerra civil, contra otros estados, enfrentamientos contra pueblos originarios. En la descripción de cada conflicto es deseable que el texto informativo incorporado directamente en la base sea breve, pero que provea toda la información de fuentes necesarias a partir de enlaces. Momentáneamente, la carga de datos en el mapa no se encuentra en una versión de acceso público ya que la estructura se encuentra en etapa de prueba y sus contenidos están siendo moderados y en proceso de edición. En el desarrollo de estas pruebas se deberá comenzar a proponer alternativas para la resolución de potenciales conflictos de datos o contradicciones de contenidos que pudieran surgir ${ }^{32}$.

En una siguiente etapa, se prevé el desarrollo de la aplicación que tendrá una interfaz de carga de datos y otra interfaz de visualización de datos. Una aplicación del Mapa Interactivo de Conflictos Armados sería también una herramienta para entender, recrear e imaginar el pasado para quienes visiten los sitios en persona y lo exploren con su celular o tablet. El usuario podría saber qué batallas y fortines se encuentran en las cercanías, mediante Google Maps, Earth View y Where To, por ejemplo. También, le permitiría visualizar in situ la reconstrucción en Realidad Aumentada de un fortín o de las posiciones militares de una batalla ${ }^{33}$, a la vez que brindará acceso en el lugar a todos los materiales acopiados en la página web propia. Y aumentará los recursos de divulgación durante la visita a museos históricos ${ }^{34}$.

En paralelo se está trabajando en el desarrollo de un plan de gestión de datos, en línea con los principios FAIR (findable, accesible, interoperable, reusable), que permita no solo el acceso sino la preservación de la información acumulada en el corpus de MICA. Asimismo, se prevé evaluar las limitaciones necesarias para proteger el patrimonio histórico y arqueológico sin que ello impida el acceso a la información.

Estando el proyecto en una etapa de testeo, no se ha implementado aún una estrategia de comunicación para el gran público. Se prevé que las páginas web y redes sociales institucionales de los autores cumplan inicialmente esta función. Desde estos mismos ámbitos ya se desarrollan diversas acciones de extensión, por cuyo contenido son potencialmente vinculables al proyecto MICA para hacerlo ir más allá de la virtualidad, y no se descarta la elaboración de otro tipo de mate-

\footnotetext{
32 En proyectos colectivos es usual apelar como criterio previo de validación a la inclusión de enlaces con otras entradas de la misma base, y a la explicitación de fuentes. Asimismo se podría proponer una jerarquía de tipos de fuentes (por ejemplo, cartografías oficiales y artículos académicos pesando más que notas periodísticas o blog personales).

33 Por ejemplo, Battlefields. Accesible desde: https://www.battlefields.org/visit/mobile-apps.

34 Por ejemplo, Battlefields. Accesible desde: https://www.battlefields.org/visit/virtual-tours.
} 
riales de difusión.

\section{CONCLUSIONES}

El recorrido realizado en este trabajo expone antecedentes que justifican la necesidad o conveniencia de un proyecto con las características generales que se proponen para MICA. En esta primera etapa, tanto las conclusiones que se pueden adelantar son necesariamente generalizadas. El desarrollo y su implementación permitirá optar por orientaciones o estrategias más específicas.

Las nuevas tecnologías de investigación y registro, sumadas a la inmensa variedad de opciones de difusión audiovisual, ambas cada vez más accesibles en término de costos, abren posibilidades de divulgación científica impensadas hasta hace pocos años. Se observa una multiplicación de medios y tecnologías cada vez más accesibles, donde se destaca que en la actualidad estos recursos son: 1) escalables (desde la geolocalización y etiquetado hasta la construcción de escenas virtuales completamente navegables) y 2 ) acumulables (en cada registro pueden combinarse materiales de apoyo con diversidad de formatos, no necesariamente creados para el proyecto, sino colectados de otras fuentes). Estas diversidad, por otro lado, requiere la constitución y organización de su base de datos de forma tal que los usuarios puedan explorarlo libremente y recorrer sus múltiples entradas de manera flexible construyendo así su propio periplo virtual.

Las posibilidades de divulgación que ofrecen las modernas tecnologías y medios de difusión desafían a los arqueólogos a aliarse con profesionales en storytelling, en fotografía, en audiovisual, en diseño y en programación para expandir su audiencia y la llegada de su producción de conocimientos. A la vez, la simplificación y el abaratamiento del acceso a los nuevos recursos de producción y edición de contenidos los estimula a capacitarse para transformarse ellos mismos en agentes activos de registro audiovisual y en creadores de narraciones tanto para el mundo académico como para un público general. La cámara lúcida de Catherwood hoy es un celular, una tablet - un dron, cuyas imágenes -organizadas como relatos- pueden trascender casi al instante en la web y en las redes sociales.

A diferencia del siglo XIX, sin embargo, la sobreabundancia de oferta informativa es el mayor problema a la hora de difundir historias de ciencia, ya que su multiplicación conspira contra la oportunidad de alcanzar a la mayor cantidad de público posible. Por eso, la creación de una base de datos avalada por instituciones e investigadores académicos con trayectoria en la temática, que albergue contenidos científicos confiables y también experiencias de narrativa visual atractivas para un público masivo es la manera de generar una posición destacada dentro del apabullante universo del contenido en la web. Un claro ejemplo son los recorridos virtuales del INAH de los principales sitios y museos arqueológicos de México ${ }^{35}$.

Gracias a las nuevas tecnologías de registro y difusión digital, MICA puede aportar los cimientos para el desarrollo de una base de datos visuales y escritos del patrimonio arqueológico e histórico de los conflictos armados en una escala espacial y temporal más amplia que la inicialmen-

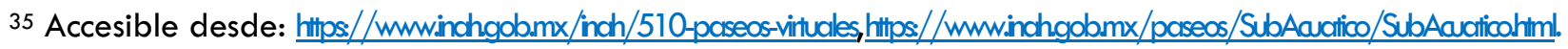


te esbozada.

En un ejercicio de Arqueología Digital participativa (Acevedo et al., 2018; Ávido \& Vitores, 2019; Staropoli et al., 2019), reconociendo el potencial de la Arqueología para apelar a las emociones (Perry, 2019) y crear narrativas que entusiasman tanto como la ciencia ficción (Morgan, 2019), el proyecto MICA busca reunir los aportes de una diversidad de actores interesados en la preservación de la memoria colectiva, que no está exenta de disputas. Así, MICA se posiciona como una herramienta que permite visibilizar distintos recortes y por ende dar lugar a distintos agentes y sus visiones. El mapa, como la memoria, es un campo de batalla.

\section{AGRADECIMIENTOS}

A la Lic. Sandra Pintos Llovet y a los Dres. Luis Coll y Ezequiel de Rosso por sus observaciones y críticas. Todo lo expresado en este artículo es absoluta responsabilidad de sus autores. A los evaluadores anónimos cuyos comentarios han permitido dar claridad a este trabajo.

\section{REFERENCIAS BIBLIOGRÁFICAS}

Acevedo, V., Staropoli, L., Herrera, N. V., Ciarlo, N., \& Landa, C. (2018). ArqueoLab-UBA, un encuentro con la Ciencia Participativa [Poster]. II Congreso de Ciencia Abierta y Ciudadana (CIACIAR 2018 - UNSAM). Universidad Nacional de San Martín. http://sedici.unlp.edu.ar/ handle/10915/81093

Ávido, D., \& Vitores, M. (2019). Observaciones sobre el proceso de documentación 3D mediante fotogrametría. En A. Laguens, M. Bonnin, B. Marconetto (Comps.), Thiago Costa da Silva (Ed.), Libro de Resúmenes XX Congreso Nacional de Arqueología Argentina: 50 años de arqueologías (pp. 1592-1596). Universidad Nacional de Córdoba. https:// suquia.ffyh.unc.edu.ar/handle/suquia/3487

Cook, K., Çakirlar, C., Goddard, T., DeMuth, R., \& Wells, J. (2018). Teaching Open Science: Published Data and Digital Literacy in Archaeology Classrooms. Advances in Archaeological Practice, 6(2), 144-156. https://doi.org/10.1017/aap.2018.5

Coll, L. (2009). De los cardos a María del Carmen de Cañuelas. Representaciones del espacio del Partido de Cañuelas, Provincia de Buenos Aires (Siglos XIX-XX) [manuscrito inédito].

Ellenberger, K. (2017). Virtual and Augmented Reality in Public Archaeology Teaching. Advances in Archaeological Practice, 5(3), 305-309. https://doi.org/10.1017/aap.2017.20

Fernández, A., \& Torres, D. (2016, marzo 1). Ciencia Ciudadana: ¿̇ué es? Didáctica y TIC. Blog de la Comunidad Virtual de Práctica Docentes en Línea. http://sedici.unlp.edu.ar/ handle/10915/60599

Gallardo Escalona, L. (2013). Open social learning Crowdmap. Building alternative ways... [Tesis de Maestría. Universidad Nacional de Educación a Distancia]. http:// hdl.handle.net/11162/184205

Greenfieldboyce, N. (2014, enero 9). There she blew! Volcanic evidence of the world's first map. Na- 
tional Public Radio. https://www.npr.org/2014/01/09/260918293/there-she-blewvolcanic-evidence-of-the-worlds-first-map

Izeta, A., \& Cattáneo, R. (2016). ¿Es posible una arqueología digital en Argentina? Un acercamiento desde la práctica. En G. del Rio Riande, G. Calarco, G. Striker \& R. De León (Eds.), Humanidades Digitales: Construcciones locales en contextos globales. Actas del I Congreso Internacional de la Asociación Argentina de Humanidades Digitales. Editorial de la Facultad de Filosofía y Letras. https://www.aacademica.org/aahd.congreso/15

Landa, C., \& Hernández de Lara, O. (2014). Sobre campos de batallas arqueología de conflictos bélicos en América Latina. Aspha Ediciones.

Lois, C. (2014). Mapas para la nación: Episodios en la historia de la cartografía argentina. Editorial Biblos.

Lois, C. (2015). El mapa, los mapas. Propuestas metodológicas para abordar la pluralidad y la inestabilidad de la imagen cartográfica. Geograficando, 11(1). http:// www.geograficando.fahce.unlp.edu.ar/article/view/Geov1 1n01a02

Morgan, C. (2019). Avatars, Monsters, and Machines: A Cyborg Archaeology. European Journal of Archaeology 22(3), 324-37. https://doi.org/10.1017/eaa.2019.22

Mortillet, G., \& Chantre, E. (1876). La légende internationale pour les cartes archéologiques préhistoriques. En Congrès International d'Anthropologie et d'Archéologie préhistoriques, Compte Rendú de la 7e Session, Stockholm 1874. P.A. Norstedt \& Söner. http:// books.google.com.ar/books?id=m-gxAQAAMAAJ

Porro Gutíerrez, J. (2011). La cartografía histórica como fuente para la investigación histórica y patrimonial (Antigüedad y Edad Media). Revista PH, 77, 54-61. https:// doi.org/10.33349/2011.77.3099

Perry, S. (2019). The Enchantment of the Archaeological Record. European Journal of Archaeology, 22(3), 354-371. https://doi.org/10.1017/eaa.2019.24

Redman, C. L. (1990). Los orígenes de la civilización. Desde los primeros agricultores hasta la sociedad urbana en el Próximo Oriente. Crítica.

Rissolo, D., Hess, M. R., Huchim Herrera, J., Lo, E., Petrovic, V., Amador, F. E., \& Kuester, F. (2019). Comprehensive digital documentation and preliminary structural assessment of satunsat: a unique Maya architectural labyrinth at Oxkintok, Yucatan, Mexico. The International Archives of the Photogrammetry, Remote Sensing and Spatial Information Sciences, XLII-2/W15, 989992. https://doi.org/10.5194/isprs-archives-XLII-2-W15-989-2019

Staropoli, L., Lanza, A., Ávido, D., \& Herrera, V. (2019). La construcción del patrimonio virtual en la investigación, conservación y difusión del pasado. En A. Laguens, M. Bonnin, B. Marconetto (Comps.), Thiago Costa da Silva (ed.), Libro de Resúmenes XX Congreso Nacional de Arqueología Argentina: 50 años de arqueologías. Universidad Nacional de Córdoba. https:// suquia.ffyh.unc.edu.ar/handle/suquia/3487

Stephens, J., \& Catherwood, F. (1993) [1854]. En busca de los Mayas. Viajes a Yucatán. (Tomos I y II). Producción Editorial Dante. 